\title{
Chemical and morphological characteristics of mineral trioxide aggregate and Portland cements
}

\author{
Shahbaz KHAN ${ }^{1,2}$, Muhammad KALEEM ${ }^{1}$, Muhammad Amber FAREED ${ }^{3,4}$, Amir HABIB ${ }^{5}$, Kefi IQBAL ${ }^{6}$, \\ Ayesha ASLAM $^{7}$ and Shahab UD DIN ${ }^{1}$ \\ ${ }^{1}$ Department of Dental Materials, Army Medical College, National University of Sciences and Technology, Islamabad, Pakistan \\ ${ }^{2}$ Department of Operative Dentistry, Bolan Medical College, University of Balochistan, Quetta, Pakistan \\ ${ }^{3}$ Biomaterials Group, Metallurgy and Materials, University of Birmingham, Birmingham, UK \\ ${ }^{4}$ Department of Science of Dental Materials, FMH College of Medicine and Dentistry, University of Health Sciences, Lahore, Pakistan \\ ${ }^{5}$ Department of Materials Science, School of Chemical and Materials Engineering, National University of Sciences and Technology, Islamabad, \\ Pakistan \\ ${ }^{6}$ Department of Dental Materials Science, Baqai Dental College, Baqai Medical University, Karachi, Pakistan \\ ${ }^{7}$ Department of Prosthodontics, Armed Forces Institute of Dentistry, National University of Sciences and Technology, Islamabad, Pakistan \\ Corresponding author, Shahbaz KHAN; E-mail: drshahbaz111@gmail.com
}

\begin{abstract}
The purpose of this study was to investigate the chemical composition and particle morphology of white mineral trioxide aggregate (WMTA) and two white Portland cements (CEM 1 and CEM 2). Compositional analysis was performed by energy dispersive X-ray spectroscopy, X-ray fluorescence spectrometry and X-ray diffraction whereas, morphological characteristics were analyzed by scanning electron microscope and Laser scattering particle size distribution analyzer. The elemental composition of WMTA, CEM 1 and CEM 2 were similar except for the presence of higher amounts of bismuth in WMTA. Calcium oxide and silicon oxide constitute the major portion of the three materials whereas, tricalcium silicate was detected as the major mineral phase. The particle size distribution and morphology of WMTA was finer compared to CEM 1 and CEM 2. The three tested materials had relatively similar chemical composition and irregular particle morphologies.
\end{abstract}

Keywords: Mineral trioxide aggregate, Portland cement, Chemistry, Morphology, Characterization

\section{INTRODUCTION}

The ideal properties of an endodontic material are biocompatibility, insolubility in tissue fluids, radiopacity, dimensional stability and prevention of communication between the root canal system and its surrounding tissues $^{1,2)}$. To fulfill these requirements Mineral Trioxide Aggregate (MTA) was introduced by Torabinejad and White in $1990 \mathrm{~s}^{3)}$. Since its introduction, MTA has gained acceptance in variety of endodontic treatments for example root end fillings, repair of lateral perforations, direct pulp capping, pulpotomy and apexification ${ }^{2,4)}$.

MTA is marketed in two forms i.e. gray MTA (GMTA) and white MTA (WMTA) ${ }^{2}$. Initially GMTA was introduced (ProRoot MTA, Dentsply Endodontics, Tulsa, OK, USA) ${ }^{5}$ but due to discoloration potential of GMTA, white form of MTA (ProRoot white MTA) was introduced ${ }^{2}$. MTA is a bioactive and biocompatible material considered for conducting and inducting hard tissue formation when used in endodontic applications $\mathrm{s}^{2,6)}$. Many studies have published comparison of MTA and other endodontic materials such as zinc oxide-eugenol, super-EBA, amalgam and glass ionomer cements ${ }^{7-11)}$ which reported that MTA was a material of choice for root-end fillings ${ }^{12}$. Despite several favorable properties, MTA is not widely used in endodontics mainly due to its poor handling characteristics, extended setting time and high $\operatorname{costs}^{2,12)}$.

It is well established that MTA is derived from an ordinary Portland cement (PC) therefore; a great deal of resemblance between the two materials exists ${ }^{2,12)}$. According to Song et al., and Asgary et al., both MTA and $\mathrm{PC}$ are chemically similar and are mainly composed of calcium and silicon ${ }^{13,14)}$. Moreover, investigation of physical characteristics of MTA and PC revealed both materials to possess comparable $\mathrm{pH}$, solubility, dimensional change and similarly long setting time ${ }^{15}$. These similarities between MTA and PC are not inadvertent since the original patent declared that $\mathrm{PC}$ is the principal component in MTA ${ }^{16)}$. Therefore, a number of studies have suggested the use of $\mathrm{PC}$ as a less expensive alternate of MTA in dental practices ${ }^{12,17,18}$. However, in contrast, several researchers disagree with the idea of using PC in dental applications and have reported differences between MTA and PC in terms of chemical composition, surface chemical characteristics, compressive strength, cation release and particle sizes $^{2,15,19-21)}$. As the potential of PC in providing an inexpensive solution to economic drawbacks of MTA is eclipsed by the controversy existing between the reported studies, there is a need to further probe in to the characterization and comparison of MTA and PC. Therefore, aims of the present study were compositional and morphological analysis of unset WMTA powder and ordinary white PCs to understand the properties and to evaluate mutual resemblance. In order to comprehensively investigate the chemical constitution of MTA and PC, the composition of elements that constitute simple oxides was investigated. Then composition of simple oxides that constitute mineral phases was 
investigated and finally, the composition of mineral phases which constitute MTA and PC were investigated. We hypothesize that both MTA and PC are similar in terms of chemical composition and particle morphology.

\section{MATERIALS AND METHODS}

In this study WMTA (ProRoot white MTA, Dentsply DeTrey, Konstantz, Germany) was used as control group, CEM 1 (Kohat super white, Kohat Cement Company Limited, Kohat, Pakistan) and CEM 2 (Maple leaf white cement, Maple leaf Cement Factory, Mianwali, Pakistan) were used as study materials.

\section{Chemical composition analysis}

The compositional analysis of powder specimens was carried out by energy dispersive X-ray spectroscopy (EDS), X-ray fluorescence spectrometry (XRF) and X-ray diffraction (XRD).

\section{EDS}

Elemental composition of powder specimens were analyzed by EDS. The powder specimen was smeared on double-sided carbon tape attached to an aluminum stub and sputtered with gold nanoparticles to enhance electrical conductance by using a high vacuum sputter coating machine (MED 5010, Balzers Union, Liechtenstein). Samples were studied using scanning electron microscopy (SEM) (JSM-6490A, JEOL, Japan) equipped with an EDS set at measurement mode of point scanning.

\section{XRF}

The composition of simple oxides and pure elements were analyzed by XRF (JSX 3202M, JEOL). The powder specimens were placed over thin film of polyethyleneterephthalate $\quad\left(\right.$ Mylar $^{\circledR}, \quad$ Chemplex industries, Palm city, FL, USA) suspended in plastic sample cups and XRF analysis was performed at $30 \mathrm{kV}$ voltage and $1.0 \mathrm{~mA}$ current.

\section{XRD}

The mineral phase compositions were studied by XRD (Theta-Theta, STOE, Germany). The powder specimens were placed on XRD sample holders and leveled with a plastic spatula to obtain even surface. The diffraction analysis was performed with $\mathrm{CuK} \alpha$ radiation at $40 \mathrm{KV}$ voltage and $40 \mathrm{~mA}$ current. The scan range was set at $10-80^{\circ} 2 \theta$ at a scan speed of $2^{\circ} 2 \theta$ per min. Phase identification was accomplished by matching the diffraction patterns with International Center for Diffraction Data (ICDD) database (International Center for Diffraction Data, Newtown Square, PA, USA).

\section{Analysis of morphology}

The particle size and morphology of powder specimens was carried out by scanning electron microscope (SEM) and laser scattering particle size distribution analyzer (LS-PSD).

\section{SEM}

Analytical microscopy for evaluating the particle morphology and size of powder specimens was performed using SEM (JSM-6490A, JEOL) at $20 \mathrm{kV}$ accelerating voltage. The digital X-ray images were acquired at $1,280 \times 960$ pixels.

\section{LS-PSD}

Particle size and distribution of powder specimens were evaluated with LS-PSD (LA-920, HORIBA, Japan) with a range of measurement between $0.022-2,000 \mu \mathrm{m}$. Samples were prepared by suspending powder specimens in $200 \mathrm{~mL}$ of $99 \%$ ethanol (refractive index-1.36 n) at $20^{\circ} \mathrm{C}$ and each suspension was sonicated for $30 \mathrm{~min}$ to evenly disperse the particles to ensure proper sonication before pouring into LS-PSD.

\section{RESULTS}

\section{Chemical composition analysis}

\section{EDS}

The EDS analysis for elemental composition of WMTA, CEM 1 and CEM 2 showed that the three materials were mainly composed of $\mathrm{O}, \mathrm{Ca}$ and $\mathrm{Si}$ and together they constituted bulk of the elemental composition of tested materials. The minor elements detected by EDS in the three materials included $\mathrm{Al}, \mathrm{Mg}, \mathrm{K}, \mathrm{Zn}$ and $\mathrm{Ba}$. Bi was detected in higher amounts in WMTA, where as it was scarcely present in CEM 1 and CEM 2 (Table 1).

\section{XRF}

Elemental analysis by XRF was in agreement to the results of EDS and confirmed that high amounts of $\mathrm{Ca}$ and $\mathrm{Si}$ were present in WMTA, CEM 1 and CEM 2. Whereas Bi was detected only in WMTA and Al was not detected in any of the material (Table 2). The simple oxide analysis by XRF was well correlated with the elemental analysis and showed calcium oxide and silicon oxide as main constituents in the three materials where as bismuth oxide was only detected in WMTA and aluminum oxide was not detected in any of the material (Table 3).

\section{XRD}

The results of XRD analysis showed that tricalcium silicate $\left(3 \mathrm{CaO} \cdot \mathrm{SiO}_{2}\right.$, produced by blending of $\mathrm{CaO}$ and $\mathrm{SiO}_{2}$ ) was the major mineral phase present in all the three materials. WMTA was composed primarily of tricalcium silicate and bismuth oxide (Fig. 1). WMTA showed strong peaks of tricalcium silicate at 29.27, 32.07, 34.26 and $41.14^{\circ} 2 \theta$ and peaks of bismuth oxide were noted at 25.64, 26.79, 27.28 and $33.13^{\circ} 20$. In CEM 1 tricalcium silicate, dicalcium silicate and bismuth oxide silicate were present. Peaks for tricalcium silicate were noted at $29.44,32.11,32.64$ and $34.30^{\circ} 2 \theta$, whereas dicalcium silicate peaks were noted at $32.11,32.64,34.30,41.15$ and $45.78^{\circ} 2 \theta$. CEM 1 showed peaks of bismuth oxide silicate at $11.55,23.29,32.64$ and $41.15^{\circ} 2 \theta$. CEM 2 was mainly composed of tricalcium silicate having peaks at $29.53,32.21,34.4541 .44$ and $51.18^{\circ} 2 \theta$. 
Table 1 Composition of elements (\%mass) present in WMTA, CEM 1 and CEM 2 evaluated by EDS (ND; not detected)

\begin{tabular}{cccc}
\hline Elements & WMTA & CEM 1 & CEM 2 \\
\hline $\mathrm{O}$ & 27.88 & 43.86 & 0.26 \\
$\mathrm{Mg}$ & 0.55 & 1.69 & 0.86 \\
$\mathrm{Al}$ & 1.19 & 8.05 & 6.4 \\
$\mathrm{Si}$ & 6.27 & 1.32 & 1.05 \\
$\mathrm{~S}$ & $\mathrm{ND}$ & 0.58 & 0.39 \\
$\mathrm{~K}$ & 0.45 & 35.86 & 38.67 \\
$\mathrm{Ca}$ & 30 & 0.14 & $\mathrm{ND}$ \\
$\mathrm{Fe}$ & 0.26 & $\mathrm{ND}$ & $\mathrm{ND}$ \\
$\mathrm{Ni}$ & 0.26 & 1.08 & 2.68 \\
$\mathrm{Cu}$ & $\mathrm{ND}$ & 2.15 & 0.44 \\
$\mathrm{Zn}$ & 0.58 & $\mathrm{ND}$ & $\mathrm{ND}$ \\
$\mathrm{Ga}$ & 0.18 & 0.87 & 0.68 \\
$\mathrm{Ba}$ & 0.92 & $\mathrm{ND}$ & 0.59 \\
$\mathrm{Ti}$ & 0.44 & 4.14 & 1.64 \\
$\mathrm{Bi}$ & 31.02 & 100 & 100 \\
\hline
\end{tabular}

Table 2 Composition of elements (\%mass) present in WMTA, CEM 1 and CEM 2 evaluated by XRF (ND; not detected)

\begin{tabular}{cccc}
\hline Elements & WMTA & CEM 1 & CEM 2 \\
\hline $\mathrm{Si}$ & 3.8139 & 9.8658 & 17.7811 \\
$\mathrm{Ca}$ & 57.9025 & 87.4701 & 79.7792 \\
$\mathrm{Ti}$ & 0.0947 & 0.9414 & 0.6635 \\
$\mathrm{~V}$ & 0.1034 & 0.0547 & 0.1092 \\
$\mathrm{Cr}$ & $\mathrm{ND}$ & 0.0619 & 0.0744 \\
$\mathrm{Mn}$ & 0.0838 & 0.101 & 0.0473 \\
$\mathrm{Fe}$ & 0.3879 & 1.114 & 0.6465 \\
$\mathrm{Sr}$ & 0.2242 & 0.2552 & 0.8988 \\
$\mathrm{Zr}$ & $\mathrm{ND}$ & 0.1359 & $\mathrm{ND}$ \\
$\mathrm{Bi}$ & 37.3896 & $\mathrm{ND}$ & $\mathrm{ND}$ \\
$\mathrm{Total}$ & 100 & 100 & 100 \\
\hline
\end{tabular}

Table 3 Composition of simple oxide (\%mass) in WMTA, CEM 1 and CEM 2 detected by XRF (ND; not detected)

\begin{tabular}{lccc}
\hline Oxides & WMTA & CEM 1 & CEM 2 \\
\hline Al oxide & ND & ND & 26.3572 \\
Si oxide & 25.2497 & 33.766 & 71.6905 \\
Ca oxide & 50.3042 & 64.3402 & 0.6414 \\
Ti oxide & 0.0832 & 0.6237 & 0.094 \\
V oxide & ND & 0.0422 & 0.0606 \\
Cr oxide & ND & 0.491 & 0.0285 \\
Mn oxide & 0.07 & 0.0233 & 0.548 \\
Fe oxide & 0.3497 & 0.537 & 0.5798 \\
Sr oxide & 0.1452 & 0.1005 & ND \\
Zr oxide & ND & 0.0761 & ND \\
Bi oxide & 23.798 & ND & 100 \\
Total & 100 & 100 & \\
\hline
\end{tabular}




\section{Analysis of morphology}

\section{SEM}

SEM images of WMTA, CEM 1 and CEM 2 showed a combination of small and coarse irregular particles.

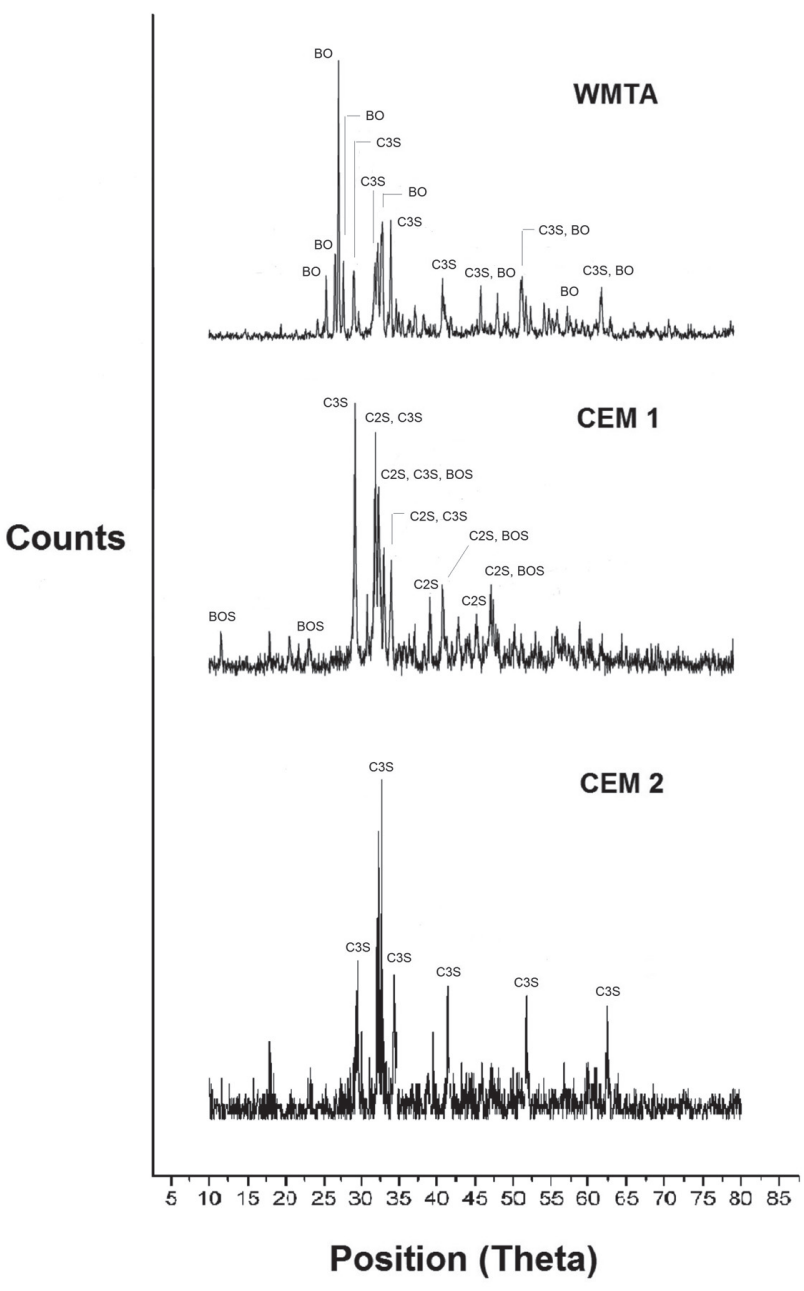

Fig. 1 XRD pattern of WMTA, CEM 1 and CEM 2 (C3S; tricalcium silicate, $\mathrm{C} 2 \mathrm{~S}$; dicalcium silicate, $\mathrm{BO}$; bismuth oxide, BOS; bismuth oxide silicate).
The particles of WMTA ranged between 1-12 $\mu \mathrm{m}$ and occasionally particles lower than $1 \mu \mathrm{m}$ were also observed. In CEM 1 the particles were observed to be distributed in wide range between $1-18 \mu \mathrm{m}$. The content of particles with less than $1 \mu \mathrm{m}$ dimension was relatively higher compared to WMTA and were observed to be loosely agglomerated. Whereas, in CEM 2 there was less particle agglomerations compared to CEM 1 and showed particle sizes between 1-20 $\mu \mathrm{m}$. The overall particle size and morphology of WMTA was refined compared to CEM 1 and CEM 2. Whereas, among the two PCs, particle morphology of CEM 2 was relatively finer and closer in resemblance to WMTA (Fig. 2).

\section{LS-PSD}

The LS-PSD analysis showed relatively different mean particle sizes of the three materials, with WMTA having the smallest particle size. LS-PSD analysis revealed mean particle size of WMTA, CEM 1 and CEM 2 as 9.08 $\mu \mathrm{m}, 10.08 \mu \mathrm{m}$ and $13.40 \mu \mathrm{m}$ respectively. In agreement to the findings of SEM, particles of WMTA were finer and observed to be distributed within a narrow range compared to CEM 1 and CEM 2 (Fig. 3).

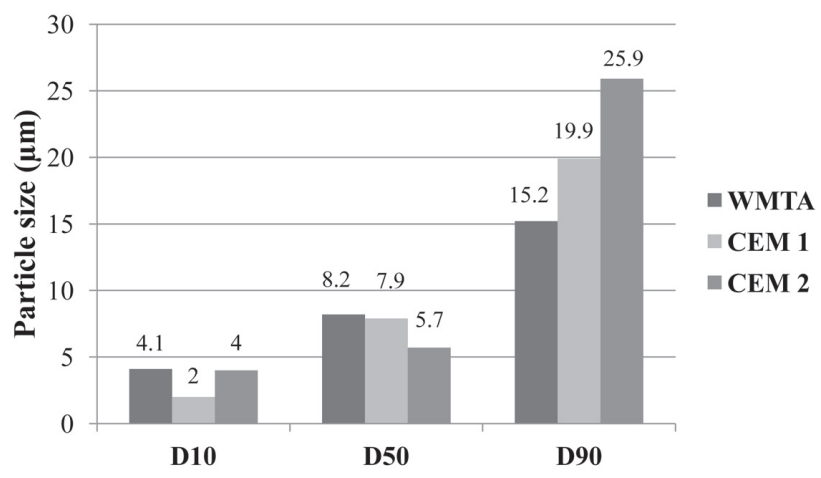

Fig. 3 Particle size distribution of WMTA, CEM1 and CEM2 evaluated by LS-PSD expressed as D10 (10\% particles below this size), D50 (50\% particles below this size) and D90 (90\% particles below this size).
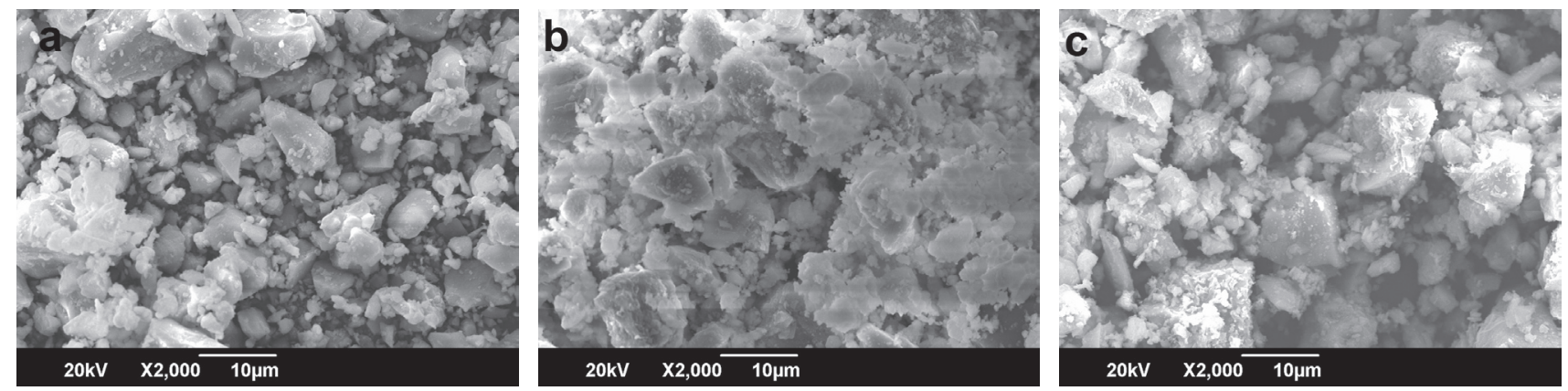

Fig. 2 SEM micrographs of (a) WMTA, (b) CEM1 and (c) CEM2 at 2,000×. 


\section{DISCUSSION}

Composition of WMTA, CEM 1 and CEM 2 was analyzed from elemental to mineral phase level. Knowing the composition of the elements, simple oxides and mineral phases that constitute WMTA and both types of PC helps in understanding their chemical, physical and biological properties. Elemental analysis by EDS and XRF confirmed that the three materials were composed of similar elements with some percentile variations (Tables 1 and 2). Ca and Si were detected as the predominant elements. This is in agreement to Dammaschke et al., which reported $\mathrm{Ca}$ and $\mathrm{Si}$ as the essential elements in the chemical composition of WMTA and white PCs ${ }^{20)}$. WMTA showed significant quantities of $\mathrm{Bi}(31.02 \%$ mass by EDS and $37.38 \%$ mass by XRF) added by manufacturer for its radiopacity. Bi exhibit high absorption of X-ray radiations used in dental diagnostics ${ }^{20)}$. Therefore, white ProRoot MTA possess radiopacity of $6.74 \mathrm{~mm}$ equivalent aluminum thickness ${ }^{15)}$. In addition, small amount of $\mathrm{Bi}$ was also detected by EDS in CEM 1 (4.14\% mass) and CEM 2 (1.64\% mass). The presence of Bi was possibly due to its existence in the raw materials used for Kilning process. Our results support Deal et al., which showed presence of $\mathrm{Bi}$ in MTA and $\mathrm{PC}^{22)}$.

Elemental analysis of WMTA and PCs revealed negligible amounts of $\mathrm{Mn}, \mathrm{Fe}, \mathrm{Ni}, \mathrm{Cu}$ and $\mathrm{Sr}$, which can reduce chances of inflammation, allergic reactions and rejection in living tissues. Al-Hiyasat et al., investigated fibroblast attachment to six different endodontic materials as measure of their biocompatibility and reported best cellular response and attachment to MTA $^{23)}$. Due to similarity of chemical composition and physical properties between MTA and PC, similar tissue response to both materials was reported by Bramante et al., after their subcutaneous implantation in mice for 15, 30 and 60 days $^{24)}$. Moreover, color of naturally occurring minerals is affected by the presence of chromophores like $\mathrm{Fe}, \mathrm{Ni}, \mathrm{Co}, \mathrm{Cr}, \mathrm{Mn}$, Ti and $\mathrm{Cu}$. Among these elements Fe is considered as the strongest chromophore and provides intensive coloring effect ${ }^{20)}$. The fewer amounts of the aforementioned elements in WMTA, CEM 1 and CEM 2 explain the white color of these materials.

There have been few studies that evaluated and compared simple oxide composition of MTA and PCs in unset form. According to Torabinejad and White, MTA is derived mainly from calcium oxide (50-75\%), silicon oxide (15-25\%) and aluminum oxide ${ }^{25)}$, similarly $\mathrm{X}$-ray fluorescence of the three tested materials showed calcium oxide and silicon oxide as the main oxide components whereas high amounts of bismuth oxide was detected in WMTA (Table 3). Although according to EDS results presence of aluminum oxide in WMTA and PCs was expected however, it was not detected in any of the material.

Phase analysis showed tricalcium silicate as the major mineral phase present in all the three materials (Fig. 1). According to Camilleri et al., white ProRoot MTA is composed primarily of tricalcium silicate and bismuth oxide whereas, gray ProRoot MTA contains tricalcium silicate, dicalcium silicate and bismuth oxide $^{5)}$. Tricalcium silicate is the most important mineral phase of $\mathrm{PC}$ and is responsible for the formation of calcium silicate hydrate and calcium hydroxide during the setting reaction ${ }^{26)}$ as,

$$
2\left(3 \mathrm{CaO} \cdot \mathrm{SiO}_{2}\right)+6 \mathrm{H}_{2} \mathrm{O} \rightarrow 3 \mathrm{CaO} \cdot 2 \mathrm{SiO}_{2} \cdot 3 \mathrm{H}_{2} \mathrm{O}+3 \mathrm{Ca}(\mathrm{OH})_{2}
$$

The constant elution of $\mathrm{Ca}$ and formation of calcium hydroxide render MTA highly alkaline ${ }^{27)}$. The released $\mathrm{Ca}$ reacts with carbon dioxide to form calcium carbonate that act as nuclei of crystallization and promotes mineralization. Moreover, higher $\mathrm{pH}$ of MTA makes the surrounding environment inhospitable for growth of bacteria ${ }^{24)}$. Phase analysis of CEM 2 revealed small quantities of dicalcium silicate and bismuth oxide silicate along with tricalcium silicate. The presence of bismuth oxide silicate can be attributed to small amounts of bismuth in CEM 2 (Table 1).

The particle size of cement affects physical properties i.e. smaller particle size results in increased surface area for reaction with mixing liquid which leads to higher early strength and ease of handling ${ }^{2)}$. Materials with similar particle size have greater mechanical strength due to reduce spreading in grit size ${ }^{28)}$. Moreover, larger mean particle size of a material is a contributing factor for its relative weakness ${ }^{29)}$. Though, the three tested materials possessed irregular particle morphologies however, SEM and LS-PSD analysis of WMTA showed finer particle size and distribution compared to CEM 1 and CEM 2 (Figs. 2 and 3). The fine particle size and distribution of WMTA is generally considered clinically advantageous in comparison to PC, because physical structure, surface characteristics and cytotoxicity of a material indicates its biocompatibility ${ }^{30)}$. Nonetheless, dental materials with smoother surfaces causes less irritation in adjacent living tissues ${ }^{31)}$. However, despite relatively coarser particles and slight chemical differences of PC, it was well tolerated by human pulp tissues and was capable to maintain pulpal vitality and inducing dentinal bridge formation when used as a medicament after pulpotomies in human primary molars ${ }^{18)}$. The results of the present study supported our hypothesis and showed that WMTA, CEM 1 and CEM 2 have comparable chemical and morphological characteristics and as far as chemical composition is concerned, the potential use of PC in in vitro and in vivo studies or even in clinical applications as a less expensive alternate of MTA is possible.

\section{CONCLUSION}

In terms of chemical composition WMTA, CEM 1 and CEM 2 were almost similar. The main chemical difference observed between WMTA and two types of PCs was the relatively greater amounts of Bi in WMTA. Morphologically, the three tested materials showed irregular particles, however, particles of WMTA were relatively homogenous and finer compared to CEM 1 and CEM 2. 


\section{REFERENCES}

1) Gartner A, Dorn S. Advances in endodontic surgery. Dent Clin North Am 1992; 36: 357-378.

2) Parirokh M, Torabinejad M. Mineral trioxide aggregate: a comprehensive literature review - part I: chemical, physical, and antibacterial properties. J Endod 2010; 36: 16-27.

3) Lee S-J, Monsef M, Torabinejad M. Sealing ability of a mineral trioxide aggregate for repair of lateral root perforations. J Endod 1993; 19: 541-544.

4) Kim RJY, Shin JH. Cytotoxicity of a novel mineral trioxide aggregated-based root canal sealer. Dent Mater J 2014; 33: 313-318.

5) Camilleri J, Montesin FE, Brady K, Sweeney R, Curtis RV, Ford TRP. The constitution of mineral trioxide aggregate. Dent Mater 2005; 21: 297-303.

6) Moretton TR, Brown CE, Legan JJ, Kafrawy A. Tissue reactions after subcutaneous and intraosseous implantation of mineral trioxide aggregate and ethoxybenzoic acid cement. J Biomed Mater Res 2000; 52: 528-533.

7) Andelin WE, Browning DF, Hsu G-HR, Roland DD, Torabinejad M. Microleakage of resected MTA. J Endod 2002; 28: 573-574.

8) Aqrabawi J. Endodontics: Sealing ability of amalgam, super EBA cement, and MTA when used as retrograde filling materials. Br Dent J 2000; 188: 266-268.

9) Pereira CL, Cenci MS, Demarco FF. Sealing ability of MTA, Super EBA, Vitremer and amalgam as root-end filling materials. Braz Oral Res 2004; 18: 317-321.

10) Sousa C, Loyola A, Versiani M, Biffi J, Oliveira R, Pascon E. A comparative histological evaluation of the biocompatibility of materials used in apical surgery. Int Endod J 2004; 37: 738-748.

11) Chong B, Pitt Ford T, Hudson M. A prospective clinical study of Mineral Trioxide Aggregate and IRM when used as rootend filling materials in endodontic surgery. Int Endod J 2003; 36: 520-526.

12) Oliveira MGd, Xavier CB, Demarco FF, Pinheiro ALB, Costa AT, Pozza DH. Comparative chemical study of MTA and Portland cements. Braz Dent J 2007; 18: 3-7.

13) Song J-S, Mante FK, Romanow WJ, Kim S. Chemical analysis of powder and set forms of Portland cement, gray ProRoot MTA, white ProRoot MTA, and gray MTA-Angelus. Oral Surg Oral Med Oral Pathol Oral Radiol Endod 2006; 102: 809815.

14) Asgary S, Parirokh M, Eghbal MJ, Brink F. A comparative study of white mineral trioxide aggregate and white portland cements using X-ray microanalysis. Aust Endod J 2004; 30: 89-92.

15) Islam I, Chng HK, Yap AUJ. Comparison of the physical and mechanical properties of MTA and Portland cement. J Endod 2006; 32: 193-197.
16) Darvell B, Wu R. "MTA" — an Hydraulic Silicate Cement: review update and setting reaction. Dent Mater 2011; 27: 407-422.

17) Abdullah D, Ford TP, Papaioannou S, Nicholson J, McDonald F. An evaluation of accelerated Portland cement as a restorative material. Biomaterials 2002; 23: 4001-4010.

18) Conti TR, Sakai VT, Fornetti APC, Moretti ABS, Oliveira TM, Lourenço Neto N, Machado MA, Abdo RC. Pulpotomies with Portland cement in human primary molars. J Appl Oral Sci 2009; 17: 66-69.

19) Camilleri J. Hydration mechanisms of mineral trioxide aggregate. Int Endod J 2007; 40: 462-470.

20) Dammaschke T, Gerth HU, Züchner H, Schäfer E. Chemical and physical surface and bulk material characterization of white ProRoot MTA and two Portland cements. Dent Mater 2005; 21: 731-738.

21) Gancedo-Caravia L, Garcia-Barbero E. Influence of humidity and setting time on the push-out strength of mineral trioxide aggregate obturations. J Endod 2006; 32: 894-896.

22) Deal B, Wenckus C, Johnson B, Fayad M. Chemical and physical properties of MTA, Portland cement, and a new experimental material, fast-set MTA. J Endod 2002; 28: 252256.

23) Al-Hiyasat AS, Al-Sa'Eed OR, Darmani H. Quality of cellular attachment to various root-end filling materials. J Appl Oral Sci 2012; 20: 82-88.

24) Bramante CM, Kato MM, Assis GFd, Duarte MAH, Bernardineli N, Moraes IG, Garcia RB, Ordinola-Zapata R, Bramante AS. Biocompatibility and setting time of CPMMTA and white Portland cement clinker with or without calcium sulfate. J Appl Oral Sci 2013; 21: 32-36.

25) Torabinejad M, White DJ. Tooth filling material and method of use. US Patent number 5,769,638; 1995.

26) Taylor H, Barret P, Brown P, Double D, Frohnsdorff G, Johansen V. The hydration of tricalcium silicate. Matériaux et Construction 1984; 17: 457-468.

27) Fridland M, Rosado R. MTA solubility: a long term study. J Endod 2005; 31: 376-379.

28) Xie D, Brantley W, Culbertson B, Wang G. Mechanical properties and microstructures of glass-ionomer cements. Dent Mater 2000; 16: 129-138.

29) Brune D, Smith D. Microstructure and strength properties of silicate and glass ionomer cements. Acta Odontol Scand 1982; 40: 389-396.

30) Zhu Q, Haglund R, Safavi KE, Spangberg LS. Adhesion of human osteoblasts on root-end filling materials. J Endod 2000; 26: 404-406.

31) Spangberg L, Langeland K. Biologic effects of dental materials: 1 . Toxicity of root canal filling materials on HeLa cells in vitro. Oral Surg Oral Med Oral Pathol Oral Radiol Endod 1973; 35: 402-414. 